\title{
Effect of spinal anterior root stimulation and sacral deafferentation on bladder and sexual dysfunction in spinal cord injury
}

\author{
Hamed Zaer ${ }^{1}$ (D) Mikkel Mylius Rasmussen ${ }^{2} \cdot$ Franko Zepke $^{3} \cdot$ Charlotte Bodin $^{2} \cdot$ Burkhard Domurath $^{3}$. \\ Johannes Kutzenberger ${ }^{3}$
}

Received: 17 February 2018 / Accepted: 3 May 2018 / Published online: 10 May 2018

(C) Springer-Verlag GmbH Austria, part of Springer Nature 2018

\begin{abstract}
Background Spinal cord injury (SCI) is a highly devastating injury with a variety of complications; among them are neurogenic bladder, bowel, and sexual dysfunction. We aimed to evaluate the effect of sacral anterior root stimulation with sacral deafferentation (SARS-SDAF) on neurogenic bladder and sexual dysfunction in a large well-defined spinal cord injury cohort.

Methods In the manner of cross-sectional study, subjects undergone SARS-SDAF between September 1986 and July 2011 answered a questionnaire concerning conditions before and after surgery in the department of Neuro-Urology, Bad Wildungen, Germany.

Results In total 287 of 587 subjects were analyzed. Median age was 49 years (range 19-80), median time from SCI to surgery was 10 years (range $0-49$ ), and from surgery to follow-up 13 years (range 1-25). Of the analyzed subjects, 100\% of both gender used SARS for bladder emptying. On the visual analogue scale (VAS) ranging from 0 to 10 (best), satisfaction with SARS-SDAF was 10 concerning bladder emptying, however 5 and 8 regarding sexual performance, for female and male users, respectively. Baseline and follow-up comparison showed a decline in self-intermittent catheterization $(p<0.0001)$, partial catheterization by attendant $(p=0.0125)$, complete catheterization and suprapubic catheterization $(p<0.0001)$, transurethral catheterization $(p<0.0011)$, and fewer cases of involuntary urine leakage $(p<0.0001)$.

Conclusions The SARS-SDAF is a beneficial multi-potential treatment method with simultaneous positive effect on multi-organ dysfunction among SCI subjects.
\end{abstract}

Keywords Spinal cord injury - Spinal anterior root stimulation $\cdot$ Neurogenic bladder $\cdot$ Bladder rehabilitation $\cdot$ Spinal deafferentation

\section{Introduction}

Spinal cord injury (SCI) is a highly devastating injury. Individuals are imposed by a variety of complications; among them are neurogenic bladder, bowel, and sexual dysfunction.

Hamed Zaer

hz@clin.au.dk

1 Department of Neurosurgery, CENSE, Aarhus University, Nørrebrogade 44, building number 10, 5th floor, 8000 Aarhus, Denmark

2 Department of Neurosurgery, CENSE-spine, Aarhus University Hospital, Aarhus, Denmark

3 Department of Neuro-Urology, Werner-Wicker-Klinik, Bad Wildungen-Reinhardhausen, Germany
The disability varies with the level of SCI [7]. The physiological impairment and emotional distress due to SCI will dramatically affect the quality of life $[9,18]$.

Spinal cord injury itself is not curable yet; therefore, treatment is mostly symptomatic [15]. Bladder emptying dysfunction due to the neurogenic detrusor activity, spastic bladder, and overactive external bladder sphincter in SCI subjects and resulting complications such as urinary tract infection (UTI), autonomic dysreflexia, and renal failure are well-known [13]. Anti-muscarinic combined with clean intermittent catheterization (CIC) as a conventional treatment is associated with the risk of UTI and continuous incontinence $[11,13]$. In case of failure, sphincterotomy is an option to decrease the resistance allowing reflex voiding in men. It is, however, also associated with incontinence and usage of condom catheters [13]. The use of botulinum-A-toxin injections is also 
limited due to costs, side effects, and the requirement of repetition [13]. Therefore, alternative treatments are sought for. One of these is altering the effect of intact neuronal networks.

Sacral anterior root stimulation (SARS) was invented by Brindley in 1976 and later expanded to include sacral deafferentation (SDAF) $[4,16]$. SARS was introduced primarily to remedy the neurogenic bladder dysfunction in SCI individuals [4] which has later been investigated by means of performing SARS-SDAF on a large cohort of paraplegic subjects with high success rates [13]. Because of common innervation from the spinal root (S2-S4), SARS can also affect the neurogenic bowel dysfunction as well as the neurogenic sexual dysfunction [15]. Intrathecal stimulation of anterior sacral root combined with SDAF by intradural rhizotomy of the afferent sacral nerves (S2-S4/S5) has been used successfully since 1986 $[4,13]$.

Most SCI subjects are in the reproductive age, and sexual complications and rehabilitation have significant consequences on their whole life [9]; however, neurogenic sexual dysfunction treatment has only been sparsely investigated so far [12].

The aim of this study is to investigate the effect of the SARS-SDAF procedure on neurogenic bladder and sexual dysfunction, following SCI in one of the largest cohorts on a global scale.

\section{Materials and methods}

The SARS procedure is previously described in detail [13, 15]. Briefly, the sacral nerve roots are dissected, the sensory (dorsal; posterior) part sacrificed, and stimulation electrodes placed intradural on the remaining sacral anterior (ventral or motor) roots (Fig. 1), which allows for a possible extradural revision surgery, smaller stimulus currents and voltages, and more focused recruitment area compared to extradural placement of electrodes [10]. A subcutaneous device, connected to the electrodes, applies a pulsatile stimulation when turned on. An external subject-controlled remote controls the stimulation with a selective programming for the bladder, bowel, and sexual functions $[13,15]$. The stimulation results in simultaneous contraction in the detrusor's soft muscles innervated by the pelvic plexus and the striated muscles of the pelvic floor innervated by the pudendal nerve. The short pulsatile stimulations and the long intervals help to keep continuity of micturition, since the striated pelvic muscle instantly relaxes by the stimulation cessation, while the smooth detrusor muscle slowly reacts, leading to poststimulus voiding [17]. The implant used was primarily intrathecal 2 or 3 channel implants (before 2001: Finetech Ltd., UK, and after 2001: RBM, Hamburg, Reinhard Becker company).

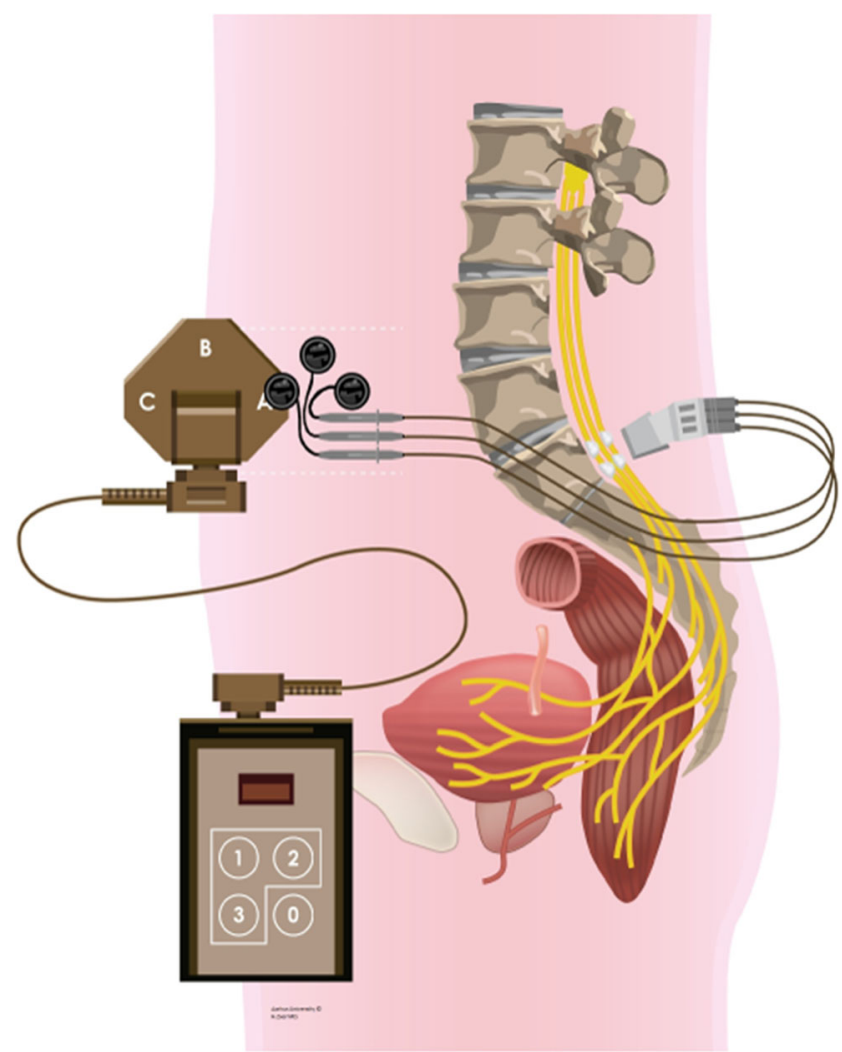

Fig. 1 SARS-SDAF schematic illustration

\section{Construction of the neurogenic bladder and sexual dysfunction questionnaires}

We based our neurogenic bladder dysfunction questionnaire on the International lower urinary tract function basic spinal cord injury data set [3]. In order to consider sexual dysfunction, we designed a questionnaire with a few supplementary items specified separately for each gender's sexual dysfunction based on the International Spinal Cord Injury Male Sexual Function Basic Data Set [1] and the International Spinal Cord Injury Female Sexual and Reproductive Function Basic Data Set [1]. All questionnaires had two parts: Part one concerned the condition before the SARS procedure and part two the present situation. Further, we adopted a visual analogue scale (VAS) with the range of zero (worst) to 10 (best), describing the subject's satisfaction with the SARS treatment and overall status of the neurogenic bladder and sexual dysfunction.

The questionnaires were translated into German by a professional translation bureau with expertise in medical translation. To ensure that the questions were fully understood by the patients, four hospitalized SCI subjects who had undergone the SARS procedure filled in the questionnaire and were then interviewed individually before finalization of the questionnaire. 
Fig. 2 Flowchart of inclusion

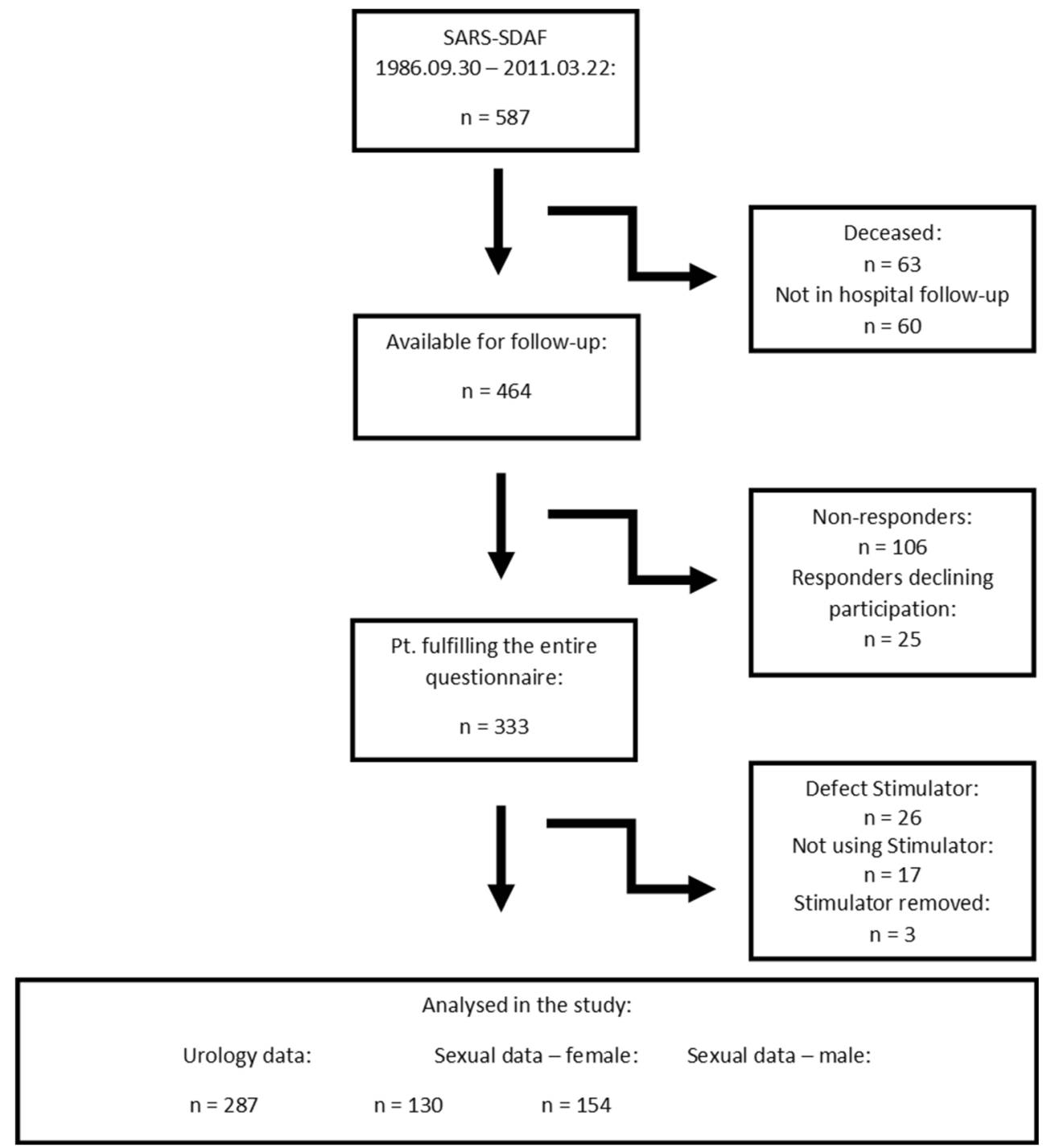

\section{Data collection}

All patients were recruited from the hospital records of patients having undergone SARS surgery at the Department of Neuro-Urology, Werner-Wicker Clinic, Bad Wildungen, Germany, between September 1986 and July 2011. All subjects still alive and available were contacted and mailed a questionnaire. The same questionnaire was mailed once more to non-responders. Baseline data were collected from hospital files.

\section{Statistical analysis}

Data analyzing by Wilcoxon signed rank test and median with 25 and $75 \%$ quartiles are given. $P$ value $<0.05$ was considered statistically significant. In order to perform test-retest analysis, an identical questionnaire was re-mailed to 40 randomly chosen responders after a mean of $2 \frac{1}{2}$ months. The test-retest analysis is published elsewhere [15].

\section{Ethical considerations}

We declare that all the relevant institutional and governmental principles regarding the ethical usage of human volunteers were obeyed through this research.

\section{Results}

Five hundred eighty-seven subjects underwent SARSSDAF from 1986 to 2011. Among operated subjects, 60 subjects were not in the hospital's follow-up program, and 63 subjects were deceased. Four hundred sixty-four patients were contacted via mail, 106 of these subjects did 
Table 1 Patients demographics

\begin{tabular}{|c|c|c|c|c|}
\hline & $\begin{array}{l}\text { Patients analyzed } \\
n=287\end{array}$ & $\begin{array}{l}\text { Range } \\
\text { (Min-max) }\end{array}$ & $\begin{array}{l}\text { Not analyzed } \\
n=300\end{array}$ & $\begin{array}{l}\text { Range } \\
\text { (Min-max) }\end{array}$ \\
\hline Age at follow-up (median, years) & 49 & $(19-80)$ & 50 & $(22-86)$ \\
\hline Time from SCI to follow-up (median, years) & 24 & $(4-56)$ & 25 & $(4-63)$ \\
\hline Time from SCI to surgery (median, years) & 10 & $(0-49)$ & 8 & $(1-42)$ \\
\hline Time from surgery to follow-up (median, years) & 13 & $(1-25)$ & 16 & $(1-25)$ \\
\hline \multicolumn{5}{|l|}{ Sex } \\
\hline Male & 154 & & 178 & \\
\hline Female & 133 & & 122 & \\
\hline \multicolumn{5}{|l|}{ AIS score } \\
\hline A & 242 & & 254 & \\
\hline $\mathrm{B}$ & 39 & & 37 & \\
\hline $\mathrm{C}$ & 6 & & 8 & \\
\hline $\mathrm{D}$ & 0 & & 1 & \\
\hline $\mathrm{E}$ & 0 & & 0 & \\
\hline \multicolumn{5}{|l|}{ Lesion level } \\
\hline Cervical & 136 & (C1-C8) & 134 & $(\mathrm{C} 2-\mathrm{C} 8)$ \\
\hline Thoracic & 148 & (Th1-Th12) & 154 & (Th1-Th12) \\
\hline Lumbar & 3 & (L1-L2) & 11 & (L1-L5) \\
\hline Sacral & 0 & & 0 & \\
\hline \multicolumn{5}{|l|}{ Etiology: } \\
\hline Traumatic SCI & 277 & & 284 & \\
\hline Spinal cord neoplasm & 5 & & 6 & \\
\hline Inflammatory disease & 4 & & 7 & \\
\hline Neural tube defect & 1 & & 3 & \\
\hline
\end{tabular}

not respond, and 25 declined to participate. In total, 333 subjects fulfilled the questionnaire. Twenty-six subjects were excluded due to stimulator defects, 17 subjects for not using the stimulator, and three patients because of stimulator removal. Urodynamic information from 287 subjects was analyzed as one group regardless of gender. All 287 subjects used SARS routinely for bladder emptying. Among responders, three patients declined to participate in the sexual part of the study; therefore, sexual data of 284 patients (130 female, 154 male) was analyzed separately for each gender (Fig. 2).

Comparing responders and non-responders, there was no significant difference among distribution of age, gender, injury level, SCI etiology, ISNSCI (International Standards for Neurological Classification of spinal cord injury) grade [8]), and chronometric data like injury to surgery/follow-up and surgery to follow-up period (Table 1).

\section{Neurogenic bladder dysfunction outcome}

We found a significant decrease in self-intermittent catheterization $(p<0.0001)$, partial catheterization by an attendant $(p=0.0125)$, and complete catheterization by an attendant $(p<0.0001)$.

Considering the necessity of using the indwelling urinary catheter, we found a significant decrease in using transurethral catheters $(p=0.0011)$ and suprapubic catheters $(p<0.0001)$. Further, there were statistically significant changes in bladder emptying methods as we observed decrement in performing external compression $(p<0.0001)$, straining $(p=0.0003)$, and voluntary/ involuntary bladder reflex triggering $(p<0.0001)$. Furthermore, the subjects reported significantly fewer incidents of involuntary urine leakage $(p<0.0001)$.

There was no statistically significant change in the capability of normal voiding [14] as a primary or supplementary method before and after surgery $(p=0.51)$.

The VAS satisfaction score using SARS displayed 10 out of 10 after SARS-SADF. Nuisance with neurogenic bladder dysfunction in a VAS score dropped from nine (range $7-10)$ to three (range $1-5)(p<0.0001)$. In addition, there was a significant decrease in usage of the prophylactic antibiotics $(p=0.0008)$ and bladder relaxant drugs $(p<0.0001)$ (Table 2). 
Table 2 Emptying details

Pre-operative $(n)$

Primary Supplementary
Follow-up (n)

$p$

Bladder emptying:

Normal voiding

Voluntary bladder reflex triggering

Involuntary bladder reflex triggering

Straining

External compression

Intermittent catheterization

Self

Partial catheterization by attendant

Catheterization by attendant

Indwelling catheter

Transurethral

Suprapubic

Brindley

Involuntary urine leakage

Other

Average number of bladder emptying per day Incontinence episodes:

More than once a day

Once a day

More than once a week

Once a week

More than once a month

Once a month

None

$\begin{array}{ll}7 & 5 \\ 105 & 20 \\ 29 & 17 \\ 16 & 17 \\ 33 & 21 \\ & \\ 105 & 13 \\ 6 & 4 \\ 35 & 11 \\ & \\ 8 & 8 \\ 21 & 10 \\ x & x \\ 81 & 68 \\ 5 & 1 \\ \text { Pre-operative } & \\ n & \text { Range }(25 \%-75 \%) \\ 5 & (5-6)\end{array}$

13
3
3
12
4

16

0

2

2

1

267

21

0

Follow-up

$\begin{array}{lll}n & \text { Range }(25 \%-75 \%) & p \\ 5 & (4-6) & <0.0001\end{array}$

$155 \mathrm{x}$

\section{7}

19

11

17

17

41

138

Use of collecting appliances for urinary incontinence

Uridome

Incontinence pads

Ostomy bag

Use of prophylactic antibiotics

Use of bladder relaxant drugs

Bladder sensation unchanged of surgery:

No
Yes

VAS satisfaction with Brindley

Use of SARS

VAS urological nuisance

$117 \quad \mathrm{x}$

165

$\begin{array}{ll}\mathrm{x} & \mathrm{x} \\ \mathrm{x} & \mathrm{x} \\ \mathrm{x} & \mathrm{x} \\ \mathrm{x} & \mathrm{x} \\ 9 & (7-10)\end{array}$

194

54

10

287

$\begin{array}{lll}90 & \mathrm{x} & <0.0001 \\ 58 & \mathrm{x} & <0.0001 \\ 1 & \mathrm{x} & 0.1573 \\ 111 & \mathrm{x} & 0.0008 \\ 19 & \mathrm{x} & <0.0001 \\ & \\ 194 & \mathrm{x} & \\ 54 & \mathrm{x} & \\ 10 & (0-10) & <0.0001 \\ 287 & \mathrm{x} & \\ 3 & (1-5) & \end{array}$

\section{Neurogenic sexual dysfunction}

\section{Female subjects}

In total, 130 women answered the questionnaire. There was no significant statistical difference before and after SARS-SDAF surgery concerning the capability of genital swelling with or without stimulation, orgasm, usage of sexual aids or medicines, and the ability to have sexual intercourse. Further, no significant change was found in the pre- and post-surgery VAS score $(p=0.22)$. Cessation of menstruation after the surgery rose significantly $(p<0.001)$ (Table 3$)$. 


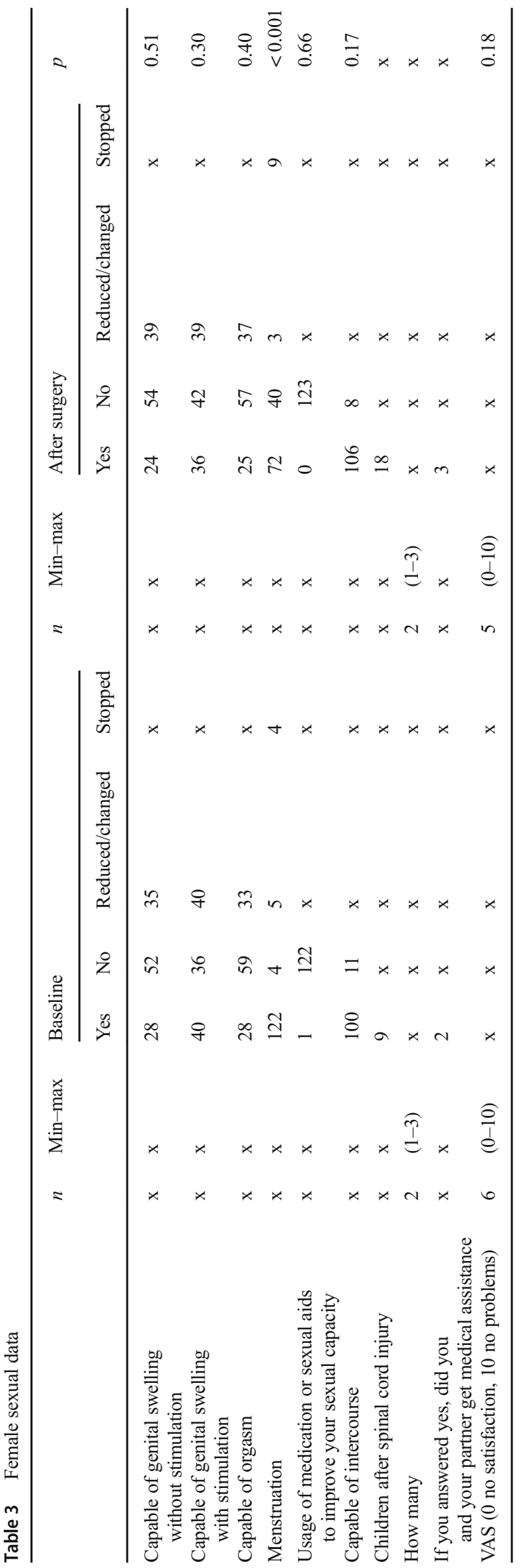

Male subjects

One hundred fifty-four men were available for data analysis. Capability of erection was significantly decreased following surgery, for both physical and non-physical stimulation $(p<0.001)$. This was also the case for the capability of ejaculation $(p<0.001)$ as well as the ability to perform intercourse without sexual aids or pharmaceutical aid $(p<0.001)$ and capability of orgasm $(p<0.001)$.

Among the 154 male subjects, 27 used SARS to enhance sexual performance $(17.5 \%)$. No significant difference was seen considering the VAS score before and after surgery $(p=0.64)($ Table 4$)$.

\section{Discussion}

SARS-SDAF is a known procedure, initially put forward as a treatment modality for neurogenic bladder dysfunction [4]. Our study is one of the largest cohorts on SARS-SDAF to date, and the findings on significant decrement of neurogenic bladder dysfunction underline the effect of the procedure and implant as an effective treatment modality in SCI patients. These findings are in line with other studies [11, 13, 17]. The high VAS satisfaction scores and lesser nuisance of bladder dysfunction affirm the positive effect of the combined SARS-SDAF on bladder function of SCI subjects. In SCI subjects, the health-related quality of life (QoL) is influenced by incontinence and UTI, and intermittent urinary catheterization is related to an increasing risk of UTI [11], a treatment modality that significantly decreased in this study.

Not surprisingly, the male sexual capability concerning reflex erection and ejaculation, and the capability of performing intercourse decreased. Therefore, the SDAF procedure, which contributes to continence by abolition of neurogenic hyperactivity or detrusor activity during filling phase and normalization of bladder capacity and compliance [11], is probably the most controversial part of the treatment. Impairment of genital and perianal sensation and deficits in reflex erection and ejaculation can be justified by the effect of bilateral deafferentation and the consequential genital and perineal sensual impairment; however, there was no difference in VAS-score before and after surgery. Unchanged VAS-score could be explained by the significant impact of SCI on sexual arousal and orgasm, indicating changes in the sexual behavior and body sensitivity of male subjects, which is profoundly affected by the spinal cord injury and perhaps less by the SARS-SDAF procedure [6]. This is probably especially true considering that the majority of patients have an ISNSCI score of A or B. However, reflex erection can be compensated in $30 \%$ of the cases through electrostimulation [17].

On the contrary, among female subjects, there was no statistically significant alteration in the sexual status, considering 
Table 4 Male sexual data

\begin{tabular}{|c|c|c|c|c|c|c|c|c|c|c|c|}
\hline & \multicolumn{5}{|c|}{ Baseline } & \multicolumn{5}{|c|}{ After surgery } & \multirow[t]{2}{*}{$p^{*}$} \\
\hline & $n$ & Min-max & Yes & No & $\begin{array}{l}\text { Reduced/ } \\
\text { changed }\end{array}$ & $n$ & Min-max & Yes & No & $\begin{array}{l}\text { Reduced/ } \\
\text { changed }\end{array}$ & \\
\hline $\begin{array}{l}\text { Capable of erection } \\
\text { without stimulation }\end{array}$ & $\mathrm{x}$ & $\mathrm{x}$ & 28 & 96 & 22 & $\mathrm{x}$ & $\mathrm{x}$ & 2 & 143 & 6 & $<0.001$ \\
\hline Capable of erection with stimulation & $\mathrm{x}$ & $\mathrm{x}$ & 79 & 24 & 45 & $\mathrm{x}$ & $\mathrm{x}$ & 15 & 112 & 23 & $<0.001$ \\
\hline Capable of ejaculation & $\mathrm{x}$ & $\mathrm{x}$ & 27 & 97 & 22 & $\mathrm{x}$ & $\mathrm{x}$ & 1 & 139 & 9 & $<0.001$ \\
\hline Capable of orgasm & $\mathrm{x}$ & $\mathrm{x}$ & 18 & 106 & 21 & $\mathrm{x}$ & $\mathrm{x}$ & 2 & 138 & 8 & $<0.001$ \\
\hline $\begin{array}{l}\text { Capable of intercourse without the } \\
\text { aid of medicine or other aids }\end{array}$ & $\mathrm{x}$ & $\mathrm{x}$ & 54 & 77 & $\mathrm{x}$ & $\mathrm{x}$ & $\mathrm{x}$ & 10 & 132 & 9 & $<0.001$ \\
\hline Usage of medication or sexual aids & $\mathrm{x}$ & $\mathrm{x}$ & 134 & 25 & $\mathrm{x}$ & $\mathrm{x}$ & $\mathrm{x}$ & 87 & 63 & $\mathrm{x}$ & $<0.001$ \\
\hline \multicolumn{12}{|l|}{ Type } \\
\hline Viagra, Cialis, Levitra & $\mathrm{x}$ & $\mathrm{x}$ & 11 & $\mathrm{x}$ & $\mathrm{x}$ & $\mathrm{x}$ & $\mathrm{x}$ & 47 & $\mathrm{x}$ & $\mathrm{x}$ & $\mathrm{x}$ \\
\hline Viridal, Ceverject (Alprostadil) & $\mathrm{x}$ & $\mathrm{x}$ & 20 & $\mathrm{x}$ & $\mathrm{x}$ & $\mathrm{x}$ & $\mathrm{x}$ & 51 & $\mathrm{x}$ & $\mathrm{x}$ & $\mathrm{x}$ \\
\hline Androskat & $\mathrm{x}$ & $\mathrm{x}$ & 22 & $\mathrm{x}$ & $\mathrm{x}$ & $\mathrm{x}$ & $\mathrm{x}$ & 62 & $\mathrm{x}$ & $\mathrm{x}$ & $\mathrm{x}$ \\
\hline Paveron & $\mathrm{x}$ & $\mathrm{x}$ & 24 & $\mathrm{x}$ & $\mathrm{x}$ & $\mathrm{x}$ & $\mathrm{x}$ & 64 & $\mathrm{x}$ & $\mathrm{x}$ & $\mathrm{x}$ \\
\hline Muse & $\mathrm{x}$ & $\mathrm{x}$ & 25 & $\mathrm{x}$ & $\mathrm{x}$ & $\mathrm{x}$ & $\mathrm{x}$ & 64 & $\mathrm{x}$ & $\mathrm{x}$ & $\mathrm{x}$ \\
\hline Penis prosthesis & $\mathrm{x}$ & $\mathrm{x}$ & 21 & $\mathrm{x}$ & $\mathrm{x}$ & $\mathrm{x}$ & $\mathrm{x}$ & 54 & $\mathrm{x}$ & $\mathrm{x}$ & $\mathrm{x}$ \\
\hline Vacuum pump & $\mathrm{x}$ & $\mathrm{x}$ & 23 & $\mathrm{x}$ & $\mathrm{x}$ & $\mathrm{x}$ & $\mathrm{x}$ & 64 & $\mathrm{x}$ & $\mathrm{x}$ & $\mathrm{x}$ \\
\hline Other & $\mathrm{x}$ & $\mathrm{x}$ & 1 & $\mathrm{x}$ & $\mathrm{x}$ & $\mathrm{x}$ & $\mathrm{x}$ & 2 & $\mathrm{x}$ & $\mathrm{x}$ & $\mathrm{x}$ \\
\hline SARS usage for sexual performance & $\mathrm{x}$ & $\mathrm{x}$ & $\mathrm{x}$ & $\mathrm{x}$ & $\mathrm{x}$ & $\mathrm{x}$ & $\mathrm{x}$ & 27 & $\mathrm{x}$ & $\mathrm{x}$ & $\mathrm{x}$ \\
\hline $\begin{array}{l}\text { Children after spinal cord injury/after } \\
\text { surgery }\end{array}$ & $\mathrm{x}$ & $\mathrm{x}$ & 7 & $\mathrm{x}$ & $\mathrm{x}$ & $\mathrm{x}$ & $\mathrm{x}$ & 7 & $\mathrm{x}$ & $\mathrm{x}$ & $\mathrm{x}$ \\
\hline How many & 2 & $(1-3)$ & $\mathrm{x}$ & $\mathrm{x}$ & $\mathrm{x}$ & 1 & $(1-9)$ & $\mathrm{x}$ & $\mathrm{x}$ & $\mathrm{x}$ & $\mathrm{x}$ \\
\hline $\begin{array}{l}\text { If you answered yes, did you and } \\
\text { your partner get medical assistance }\end{array}$ & $\mathrm{x}$ & $\mathrm{x}$ & 6 & $\mathrm{x}$ & $\mathrm{x}$ & $\mathrm{x}$ & $\mathrm{x}$ & 8 & $\mathrm{x}$ & $\mathrm{x}$ & $\mathrm{x}$ \\
\hline $\begin{array}{l}\text { VAS ( } 0 \text { no satisfaction, } \\
10 \text { no problems) }\end{array}$ & 0.41 & 0.42 & 0.43 & 0.44 & 0.45 & 0.47 & 0.48 & 0.49 & 0.50 & 0.51 & 0.53 \\
\hline
\end{tabular}

the genital swelling, orgasm, and the ability of intercourse as well as VAS-score. It can be justified by the theory that the women's sexual cycle including the arousal phase and orgasm is more controlled by mental excitements, and they do not measure their sexual arousal by physical symptoms [2]. It is also probable that the results are influenced by the fact that female SCI subjects do not have the same physical disabilities as males, which may prevent them from performing intercourse after a SCI or SDAF procedure.

The present study is one of the largest cohorts so far investigating the SARS-SDAF sexual and urodynamic effects. Two hundred eighty-seven of the 587 subjects having undergone surgery were evaluated. Although we did not find any notable difference in their baseline data comparing to data from nonresponders, selection bias cannot be excluded, i.e., the responders may be the subjects most satisfied.

Even though several studies have shown the positive effect of the SARS procedure especially on neurogenic bladder dysfunction [11, 13, 17], some restrictions in usage should be noted. Boundaries like a steep surgical learning curve, subject selection, troubleshooting, stimulator setup, and surgical procedure complications such as cerebrospinal fluid leakage or infection have limited the usage of SARS-SDAF, although it was invented more than three decades ago [15]. According to the abovementioned disadvantages, minimally invasive stimulation methods like temporary transcutaneous peripheral nerve stimulation on tibial or pudendal nerves as well as intravesical stimulation may have the upper hand and have shown some benefits in lower urinary tract management. However, the effect of those methods lasts for a short time: up to 1 year for peripheral nerve stimulation and even less for intravesical stimulation [19]. Dorsal genital nerve stimulation (GNS) and penile vibration have both shown decrement of detrusor over-activity, but until now in small cohorts of patients. The tolerance limitation among subjects and lack of data especially in female subjects considering GNS are other limitations [5]. SARS-SDAF as a multi-potential method is also beneficial to neurogenic bowel dysfunction, which is not achievable by peripheral stimulation [15]. Some studies suggest irreversible deafferentation with a negative effect on bladder sensation, bowel, and sexual function is often poorly accepted by patients with SCI and might be one of the reasons for a decline in clinical use [19]. However, all the subjects in our study have used the 
stimulator routinely for bladder emptying with a high satisfaction despite the SDAF procedure.

Although our findings are emphasized by the long-term follow up, the SARS-SDAF procedure still lacks a prospective comparative study to confirm the suggested benefits of the procedure.

Our study contributes, in line with the results of former studies, to clarify the simultaneous positive effect of the SARS-SDAF on the improvement of the neurogenic urodynamic dysfunction in SCI and seems to outline little impact on sexual dysfunction. This suggests SARS-SDAF as one of the few multi-potential treatment methods in SCI subjects.

\section{Compliance with ethical standards}

Conflict of interest The authors declare that they have no conflict of interest.

Ethical approval All procedures performed in studies involving human participants were in accordance with the ethical standards of the institutional and/or national research committee (name of institute/committee) and with the 1964 Helsinki declaration and its later amendments or comparable ethical standards.

For this type of study, formal consent is not required.

\section{References}

1. Alexander MS, Biering-Sorensen F, Elliott S, Kreuter M, Sonksen J (2011) International spinal cord injury female sexual and reproductive function basic data set. Spinal Cord 49:787-790. https://doi. org/10.1038/sc.2011.7

2. Basson R (2000) The female sexual response: a different model. J Sex Marital Ther 26:51-65. https://doi.org/10.1080/ 009262300278641

3. Biering-Sorensen F, Craggs M, Kennelly M, Schick E, Wyndaele JJ (2008) International lower urinary tract function basic spinal cord injury data set. Spinal Cord 46:325-330. https://doi.org/10.1038/sj. sc. 3102145

4. Brindley GS (1993) History of the sacral anterior root stimulator, 1969-1982. Neurourol Urodyn 12:481-483

5. Brose SW, Bourbeau DJ, Gustafson KJ (2017) Genital nerve stimulation is tolerable and effective for bladder inhibition in sensate individuals with incomplete SCI. J Spinal Cord Med 1-8. https:// doi.org/10.1080/10790268.2017.1279817

6. Cardoso FL, Savall AC, Mendes AK (2009) Self-awareness of the male sexual response after spinal cord injury. Int J Rehabil Res 32: 294-300. https://doi.org/10.1097/MRR.0b013e3283106ab7
7. Chen D, Apple DF Jr, Hudson LM, Bode R (1999) Medical complications during acute rehabilitation following spinal cord injurycurrent experience of the model systems. Arch Phys Med Rehabil 80:1397-1401

8. Emmons RR, Garber CE, Cirnigliaro CM, Kirshblum SC, Spungen AM, Bauman WA (2011) Assessment of measures for abdominal adiposity in persons with spinal cord injury. Ultrasound Med Biol 37:734-741. https://doi.org/10.1016/j.ultrasmedbio.2011.02.002

9. Fisher TL, Laud PW, Byfield MG, Brown TT, Hayat MJ, Fiedler IG (2002) Sexual health after spinal cord injury: a longitudinal study. Arch Phys Med Rehabil 83:1043-1051. https://doi.org/10.1053/ apmr.2002.33654

10. Huang Q, Oya H, Flouty OE, Reddy CG, Howard MA 3rd, Gillies GT, Utz M (2014) Comparison of spinal cord stimulation profiles from intra- and extradural electrode arrangements by finite element modelling. Med Biol Eng Comput 52:531-538. https://doi.org/10. 1007/s11517-014-1157-7

11. Krasmik D, Krebs J, van Ophoven A, Pannek J (2014) Urodynamic results, clinical efficacy, and complication rates of sacral intradural deafferentation and sacral anterior root stimulation in patients with neurogenic lower urinary tract dysfunction resulting from complete spinal cord injury. Neurourol Urodyn 33:1202-1206. https://doi. org/10.1002/nau.22486

12. Kreuter M, Taft C, Siosteen A, Biering-Sorensen F (2011) Women's sexual functioning and sex life after spinal cord injury. Spinal Cord 49:154-160. https://doi.org/10.1038/sc.2010.51

13. Kutzenberger J (2007) Surgical therapy of neurogenic detrusor overactivity (hyperreflexia) in paraplegic patients by sacral deafferentation and implant driven micturition by sacral anterior root stimulation: methods, indications, results, complications, and future prospects. Acta Neurochir Suppl 97:333-339

14. Levi R, Ertzgaard P (1998) Quality indicators in spinal cord injury care: a Swedish collaborative project. The Swedish Spinal Cord Injury Council 1998. Scand J Rehabil Med Suppl 38:1-80

15. Rasmussen MM, Kutzenberger J, Krogh K, Zepke F, Bodin C, Domurath B, Christensen P (2015) Sacral anterior root stimulation improves bowel function in subjects with spinal cord injury. Spinal Cord 53:297-301. https://doi.org/10.1038/sc.2015.2

16. Sauerwein D (1990) Surgical treatment of spastic bladder paralysis in paraplegic patients. Sacral deafferentation with implantation of a sacral anterior root stimulator. Urologe A 29:196-203

17. Seif C, Junemann KP, Braun PM (2004) Deafferentation of the urinary bladder and implantation of a sacral anterior root stimulator (SARS) for treatment of the neurogenic bladder in paraplegic patients. Biomed Tech (Berl) 49:88-92. https://doi.org/10.1515/BMT. 2004.018

18. Vastenholt JM, Snoek GJ, Buschman HP, van der Aa HE, Alleman ER, Ijzerman MJ (2003) A 7-year follow-up of sacral anterior root stimulation for bladder control in patients with a spinal cord injury: quality of life and users' experiences. Spinal Cord 41:397-402. https://doi.org/10.1038/sj.sc.3101465

19. Wyndaele JJ (2016) The management of neurogenic lower urinary tract dysfunction after spinal cord injury. Nat Rev Urol 13:705-714. https://doi.org/10.1038/nrurol.2016.206 